\title{
Canal Cleanliness and Smear Layer Removal Using Different Irrigant Activation Methods - A Scanning Electron Microscopy Study
}

\author{
Aishwarya Das ${ }^{1}$, Iffat Nasim² \\ 1Department of Conservative Dentistry and Endodontics, Saveetha Dental \\ College, Chennai Tamil Nadu, India. ${ }^{2}$ Department of Conservative Dentistry and \\ Endodontics, Saveetha Dental College, Chennai, Tamil Nadu, India.
}

\section{ABSTRACT}

\section{BACKGROUND}

Irrigation is one the most important aspects during root canal treatment of the teeth which can be achieved by mechanical cleaning and shaping with the aid of irrigants. However, the irrigant does not travel to all the places of the root canal especially the apical third. Hence, to make this irrigant reach the apical third, we need irrigant activation methods which will agitate the irrigant and help in accessing the places which are difficult to reach in the root canal system. The objective of this research was to check the canal cleanliness and the removal of the debris after irrigant activation using manual dynamic agitation (MDA), plastic F file, sonic irrigation (SI) and conventional syringe irrigation (CSI).

\section{METHODS}

Sixty single rooted teeth were chosen for this study which were biomechanically prepared using ProTaper system (Dentsply Maillefer, USA) up to a preparation of F2 and $3 \% \mathrm{NaOCl}$ and $17 \%$ EDTA were used as irrigants. All the samples were equally divided into groups of fifteen each depending on the mode of irrigant activation method used - Group 1, Manual Dynamic Agitation (MDA); Group 2, plastic F file; Group 3, EndoActivator (SI); and Group 4, control group (C). These teeth were then split along the long axis and were observed under the SEM for any debris and to determine the degree of canal cleanliness.

\section{RESULTS}

Group 4 (control group) showed the maximum debris under SEM with a statistically significant difference with a $\mathrm{P}$ value less than 0.05 ; next was the manual dynamic agitation group. Plastic $\mathrm{F}$ file group and sonic irrigation groups showed almost similar results in terms of debris.

\section{CONCLUSIONS}

Irrigant activated using sonic mode and plastic F file efficiently removed the debris in comparison to the other two groups of syringe irrigation and manual dynamic agitation.

\section{KEY WORDS}

Manual Dynamic Agitation, Plastic F File, Scanning Electron Microscopy, Smear Layer, Sonic Irrigation

\author{
Corresponding Author: \\ Dr. Aishwarya Das, \\ Mahalaxmi Flats, Besant \\ Nagar, Chennai, Tamil Nadu, India. \\ E-mail: aishwarya.das@gmail.com
}

DOI: $10.14260 /$ jemds/2020/627

How to Cite This Article:

Das A, Nasim I. Canal cleanliness and smear layer removal using different irrigant activation methods - a scanning electron microscopy study. J Evolution Med Dent Sci 2020;9(39):2866-2869, DOI: $10.14260 /$ jemds/2020/627

Submission 25-06-2020,

Peer Review 18-08-2020,

Acceptance 25-08-2020,

Published 28-09-2020.

Copyright (C) 2020 Aishwarya Das et al. This is an open access article distributed under Creative Commons Attribution License [Attribution 4.0 International (CC BY 4.0)] 


\section{BACKGROUND}

Irrigation is the most important aspect during the biomechanical preparation of the root canal system, because it is the irrigant which reaches all the parts of the canal as the instrument alone can't do so. ${ }^{1}$ The shape and morphology of the canal is such that no instrument can alone achieve all the required cleaning and disinfection. An irrigant helps to exclude the micro - organisms, other debris and unwanted content from the canal which if not removed can block the dentinal tubules which in turn will prevent the intra canal medicament and the obturating material to fully penetrate the tubules and achieve good disinfection and a good seal later. Typically, a smear layer consists of organic material, inorganic material and necrotic remains. ${ }^{2}$ Hence a combination of irrigants which can dissolve organic matter and an irrigant dissolving inorganic matter should be used for eliminating the smear layer. Hence sodium hypochlorite and EDTA are the most ideal ones. How much ever efficient these irrigants are they are not effective until they reach all parts of the root canal and remove all the microbes and debris. The long term success of the root canal treatment depends on successful elimination of the smear layer because any remaining debris can lead to reinfection and necessitate a retreatment of the previously treated root canal teeth.

The irrigants which are used must be in physical contact with the root canal wall in order to achieve the required cleanliness. When a syringe is used for irrigating the canal, the irrigant in it does not go beyond the tip of the needle. ${ }^{3}$ The trapped air in the apical one third creates a kind of air pocket called vapour lock and prevents the irrigant from reaching the apical part of the canal. Hence the need to activate or agitate these irrigants so that they can break the vapour lock and reach the apical part. ${ }^{4}$ Manual dynamic activation (MDA) is the most widely used and cheapest methods to efficiently clean the root canal system In this technique, an appropriately fitting gutta percha is repeatedly inserted two to three mm short of the working length and agitated. This selected gutta percha is moved up and down vigorously which will eventually agitate the irrigant. ${ }^{5}$ This helps to dislodge or disturb the vapour lock which is formed in the apical third of the canal. 6 The plastic $F$ file (Engineered Endodontics, WI) is an endodontic polymer based rotary file which has been introduced for root canal debridement. It is a sterile, single use, fine diamond coated plastic rotary file used to agitate the irrigant in the canal to remove remaining dentinal debris from the root canal. The EndoActivator which is based on sonic energy is quite efficient in achieving a good level of cleanliness in the root canal. The EndoActivator is light weight and easy to use which when used vigorously activates a polymerised tip. These tips are so designed that their shape and configuration matches the final prepared root canal. These tips are non - abrasive or non cutting in nature. ${ }^{7}$ The frequency at which the EndoActivator operates ranges from one to ten kilohertz.

The objective of this study was to evaluate the canal cleanliness after the mode of final irrigant activation technique using EndoActivator, syringe irrigation, manual activation, and plastic F file. The null hypothesis assumed for this study was there is no amongst the various techniques used. The alternate hypothesis was there is a significant difference using different irrigant activation techniques in smear layer removal.

\section{METHODS}

The institution ethical committee of Saveetha Dental College gave approval for this study (IHEC / SDC - ENDO - 1829 / 20 / 181 ) in the scientific review board meeting. The sample size was calculated and a total of sixty extracted human maxillary and mandibular single rooted teeth were selected. Conventional access opening was done. The canals were located and working length was determined. The initial glide path was prepared with hand K files (Mani, Japan) number 15 and number 20. ProTaper rotary system (Dentsply Maillefer, USA) was used for canal preparation and each canal was prepared up to an apical preparation of F2 size. $3 \%$ sodium hypochlorite was used as an irrigant during cleaning and shaping. The selected teeth were grouped into four groups of 15 teeth based on the irrigant activation mode used -

- Group A - Manual dynamic agitation group.

- Group B - Plastic F file group.

- Group C - EndoActivator group.

- Group D - Conventional irrigation group.

$1 \mathrm{~mL}$ of $17 \%$ EDTA was used as the final rinse followed by saline rinse for all the groups. In Group A, the irrigant was agitated for 100 small vertical strokes over a period of 1 minute using 30.06 gutta percha followed by $1 \mathrm{~mL}$ of $17 \%$ EDTA and saline as the final rinse. In Group B, the plastic F file was used to agitate the irrigant using the endomotor (X Smart, Dentsply) with handpiece. The irrigant was agitated for a period of 1 minute using the plastic $\mathrm{F}$ file according to the manufactures' instructions followed by $1 \mathrm{~mL}$ of $17 \%$ EDTA and saline as the final rinse. A new file was used for agitation in every root canal. The file tip is equivalent to a size of $20 \mathrm{~K}$ file with a taper of 0.04 . In Group C, the EndoActivator was used. The irrigant was agitated for a period of 1 minute using the EndoActivator tip size of 25 / 04 size followed by $1 \mathrm{~mL}$ of $17 \%$ EDTA and saline as the final rinse. In Group D, the conventional group, a normal 26-gauge needle was used for irrigation, followed by $1 \mathrm{~mL}$ of $17 \%$ EDTA and saline as the final rinse. In this group, no irrigant activation was performed.

The teeth used for this study were then split along their long axis and the observations were made under a microscope. The teeth were split using a diamond disc. The images which were obtained were analysed by another person who was not aware about the groups to which these images belonged to and these images were then evaluated for smear layer presence. The amount of smear layer remaining on the surface of the root canal or in the dentinal tubules was scored according to the following criteria given by Hulsmann et al: $0=$ no smear layer: No smear layer was detected on the surface of the root canals and all tubules were clean and open; 1 = moderate smear layer: No smear layer was observed on the surface of the root canal, but tubules contained debris; and $2=$ heavy smear layer. 


\section{Statistical Analysis}

Results obtained were tabulated and were statistically analysed using SPSS software (SPSS Inc, Chicago). The mean values were compared by one - way ANOVA and Tukey's honest significant difference. Multiple comparison tests by the post - hoc procedure were employed for comparison among the groups. Significance level was set at $\mathrm{P}=0.05$.

\section{RESULTS}

According to the findings made in this study, following results can be deduced - removal of smear layer was significantly more in Group C than Group A (P = 0.038, < 0.05). There was statistically significant difference between Group A and Group $\mathrm{D}(\mathrm{P}<0.0001)$ [Table 2], showing that manual dynamic agitation was better than the simple irrigation system. There was no statistically significant difference between Group B and Group C. Amongst all the experimental groups of this study, the conventional syringe irrigation group showed the maximum smear layer in the root canal walls. The difference in the presence of smear layer was statistically significant in the conventional syringe group as compared to the other groups $(P<0.0001)$. There was statistically significant difference between Group A and Group C, $(\mathrm{P}=0.038,<0.05)$. There was no statistically significant difference between the Group $B$ and Group C $(\mathrm{P}=0.677,>0.05)$. Hence, the null hypothesis was rejected since there was a statistically significant difference between the groups.

\begin{tabular}{|lcccccc|}
\hline $\begin{array}{l}\text { Groups } \\
\text { Group A } \\
\text { (MDA) }\end{array}$ & Sample Size & Mean & S.D. & Standard Error & Min. Max. \\
$\begin{array}{c}\text { Group B } \\
\text { (F file) }\end{array}$ & 15 & 0.90 & 0.316 & 0.100 & 0 & 1 \\
$\begin{array}{c}\text { Group C } \\
\text { (Sonic } \\
\text { Irrigation) }\end{array}$ & 15 & 0.60 & 0.516 & 0.163 & 0 & 1 \\
$\begin{array}{l}\text { Group D } \\
\text { (Control) } \\
\text { Total }\end{array}$ & 15 & 0.40 & 0.516 & 0.163 & 0 & 1 \\
\hline \multicolumn{7}{|c|}{ Table 1. Smear Layer Removal Ability of Various Groups } \\
\hline
\end{tabular}

\begin{tabular}{|c|c|c|c|c|c|}
\hline & $\begin{array}{c}\text { Sum of } \\
\text { Squares }\end{array}$ & $\begin{array}{l}\text { Degree of } \\
\text { Freedom }\end{array}$ & Mean Square & $\mathbf{F}$ & Anova $P$ \\
\hline $\begin{array}{c}\text { Between } \\
\text { Groups }\end{array}$ & 15.275 & 3 & 5.092 & 32.158 & $<0.0001$ \\
\hline $\begin{array}{l}\text { Within } \\
\text { Groups }\end{array}$ & 5.700 & 36 & 0.158 & & \\
\hline Total & 20.975 & 39 & & & \\
\hline \multicolumn{6}{|c|}{ Table 2. Inter Group Comparison (ANOVA) } \\
\hline
\end{tabular}

\begin{tabular}{|c|c|c|c|c|c|c|}
\hline $\begin{array}{l}\text { Group } \\
\text { (I) }\end{array}$ & $\begin{array}{c}\text { Group } \\
\text { (J) }\end{array}$ & $\begin{array}{c}\text { Mean } \\
\text { Difference } \\
\text { (I - J) }\end{array}$ & $\begin{array}{l}\text { Standard } \\
\text { Error }\end{array}$ & $\mathbf{P}$ & $\begin{array}{l}95 \% \text { CI } \\
\text { (Lower } \\
\text { Bound) }\end{array}$ & $\begin{array}{l}95 \% \text { CI } \\
\text { (Upper } \\
\text { Bound) }\end{array}$ \\
\hline MDA & F File & 0.30 & 0.178 & 0.046 & -0.18 & 0.78 \\
\hline MDA & SI & 0.50 & 0.178 & 0.038 & 0.02 & 0.98 \\
\hline MDA & Control & -1.10 & 0.178 & $<0.0001$ & -1.58 & -0.62 \\
\hline F File & SI & 0.20 & 0.178 & 0.677 & -0.28 & 0.68 \\
\hline F File & Control & -1.40 & 0.178 & $<0.0001$ & -1.88 & -0.92 \\
\hline SI & Control & -1.60 & 0.178 & $<0.0001$ & -2.08 & -1.12 \\
\hline \multicolumn{7}{|c|}{$\begin{array}{c}\text { Table 3. Multiple Comparisons of Apical Third Score } \\
\text { by Tukey Honest Significance Difference }\end{array}$} \\
\hline
\end{tabular}

\section{DISCUSSION}

Smear layer consists of dentin and also the remnants of odontoblastic processes, pulp tissue and bacteria. Mader et al. ${ }^{8}$ have elucidated that the smear layer can be broadly divided into types as the top layer and the debris which are present within the dentinal tubules. These debris can be present to a depth of fifty to sixty micro metres. It was demonstrated that bacteria can survive and multiply in the smear layer. ${ }^{9}$ The very presence of any smear layer limits the efficient percolation of the intracanal medicaments like calcium hydroxide hence can lead to ineffective disinfection of the root canal and later can also hinder the irrigants like sodium hypochlorite from cleaning every part of the canal. ${ }^{10}$ Therefore it is necessary to eliminate this smear layer.

The objective of this study was to differentiate between various irrigant agitation methods to remove the debris from the root canals of extracted single rooted teeth.

Scanning electron microscopy was chosen because it has been used to determine the effectiveness of various irrigants to remove the smear layer. In a survey by Gopikrishna et al. ${ }^{11}$ regarding irrigation protocol revealed that $68 \%$ of the respondents attempt to remove the smear layer.

The shaping of root canal with various instruments is followed by thorough cleaning of the root canal using passive sonic / ultrasonic else simply with the aid of a conventional syringe. ${ }^{12}$ Manual dynamic agitation is relatively newer than the different debridement systems that have been used in the past. The manual dynamic agitation is done with either a master cone or a syringe at 100 vibrations per minute, in order to agitate the irrigant solution inside the root canal to remove remaining dentin smear layer. The use of MDA for irrigation seems beneficial and cost - effective because no separate equipment is required for irrigation as it can be done by the same size master cones as the master apical file used for shaping and cleaning of the root canal.

There are limited studies in the literature comparing different irrigation methods with the manual dynamic agitation. There is a lack of information about the effectiveness of manual dynamic agitation to remove the smear layer from irregular canal extensions in comparison with other irrigation methods. However, Saber et al. (2011) ${ }^{13}$ found little difference between the manual dynamic agitation and the ultrasonically activated number $20 \mathrm{~K}$ - file in removal of the smear layer. ${ }^{14,15,16}$

EndoActivator which is based on sonic irrigation works at comparatively lower frequency range of one to ten kilohertz. The speed at which the irrigant moves is also lower. The sonic instruments display oscillations when in use with the node being at the attachment of the polymer tip and the antinode being at the tip of the same file. The Endo Activator system provides deeper penetration of irrigant which can reach all the inaccessible parts of the root canal and effectively cleans debris from lateral canals and dislodges clumps of simulated biofilm (Caron 2007). A possible explanation for irrigant activation giving cleaner canals is that higher frequency results in higher flow velocity which helps in dislodging the debris more effectively. In one study, ${ }^{17}$ passive activation of endodontic files for irrigation with sonic energy in canals, for as little as $30 \mathrm{~s}$ after hand instrumentation, produced canals with significantly less smear layer than canals instrumented by hand filing alone with syringe irrigation. In another study ${ }^{18}$ EndoActivator proved to be equally good as EndoVac in removing the smear layer. In our study, EndoActivator has shown statistically significant better results than manual 
dynamic agitation. It is one of the most effective methods of irrigant activation.

Plastic F file is relatively newer as compared to the other debridement systems that have been used. The plastic F file used in this study is $20 \mathrm{~mm}$ in length and has a taper of 0.04 . This mostly corresponds to the cleaned and shaped canal and has space around the file to effectively agitate the solution. In the present research it proved to be equally effective as sonic irrigation. The basic design is an abrasive coated onto a suitable nontoxic polymer that enables the new endodontic polymer based rotary finishing file to agitate the irrigant effectively and remove remaining dentinal debris without further enlarging the canal. ${ }^{19,20}$ Along with oscillatory motion, it produces a rotary motion also which creates a stress in the irrigant which becomes agitated well travels between the file and the canal wall and effectively cleans these spaces. This helps a lot to remove the smear layer. Hence it can be effectively used for irrigant activation. Also, it doesn't require any special equipment for functioning. ${ }^{21}$ It can be used in conjunction with any file system.

\section{CONCLUSIONS}

Plastic F file is equally effective as EndoActivator for the removal of smear layer. Hence plastic $F$ file can be used alternatively for irrigant activation. Owing to its cost and ease of use, we can use it routinely in our endodontic practice. Irrespective of whatever system we select, irrigant activation is mandatory in routine endodontic procedures.

Additional data for this study can be obtained from the corresponding author.

Financial or Other Competing Interests: None.

\section{REFERENCES}

[1] McComb D, Smith DC. A preliminary scanning electron microscopic study of root canals after endodontic procedures. J Endod 1975;1(7):238-42.

[2] Svec TA, Harrison JW. Chemomechanical removal of pulpal and dentinal debris with sodium hypochlorite and hydrogen peroxide vs normal saline solution. J Endod 1977;3(2):49-53.

[3] Heard F, Walton RE. Scanning electron microscope study comparing four root canal preparation techniques in small curved canals. Int Endod J 1997;30(5):323-31.

[4] Chow TW. Mechanical effectiveness of root canal irrigation. J Endod 1983;9(11):475-9.

[5] Desai P, Himel V. Comparative safety of various intracanal irrigation systems. J Endod 2009;35(4):545-9.

[6] Gu LS, Kim JR, Ling J, et al. Review of contemporary irrigant agitation techniques and devices. J Endod 2009;35(6):791-804.
[7] Jensen SA, Walker TL, Hutter JW, et al. Comparison of the cleaning efficacy of passive sonic activation and passive ultrasonic activation after hand instrumentation in molar root canals. J Endod 1999;25(11):735-8.

[8] Mader CL, Baumgartner JC, Peters DD. Scanning electron microscopic investigation of the smeared layer on root canal walls. J Endod 1984;10(10):477-83.

[9] Ciucchi B, Khettabi M, Holz J. The effectiveness of different endodontic irrigation procedures on the removal of the smear layer: a scanning electron microscopic study. Int Endod J 1989;22(1):21-8.

[10] Wu MK, van der Sluis LWM, Wesselink PR. The capability of two hand instrumentation techniques to remove the inner layer of dentine in oval canals. Int Endod J 2003;36(3):218-24.

[11] Gopikrishna V, Pare S, Kumar ARP, et al. Irrigation protocol among endodontic faculty and post-graduate students in dental colleges of India: a survey. J Conserv Dent 2013;16(5):394-8.

[12] Martin H, Cunningham WT, Norris JP, et al. Ultrasonic versus hand filing of dentin: a quantitative study. Oral Surg Oral Med Oral Pathol 1980;49(1):79-81.

[13] Saber SED, Hashem AAR. Efficacy of different final irrigation activation techniques on smear layer removal. J Endod 2011;37(9):1272-5.

[14] Mancini M, Cerroni L, Iorio L, et al. Smear layer removal and canal cleanliness using different irrigation systems (EndoActivator, EndoVac, and passive ultrasonic irrigation): field emission scanning electron microscopic evaluation in an in vitro study. J Endod 2013;39(11):1456-60.

[15] Topçuoglu HS, Akti A, Düzgün S, et al. Effectiveness of different irrigation procedures for removal of dentin debris from a simulated internal resorption cavity. Int J Artif Organs 2015;38(3):165-9.

[16] Ferreira NS, Camargo CHR, Palo RM, et al. Comparison of the effectiveness of 3 irrigation devices for the cleaning of root canal walls instrumented with oscillatory and rotary techniques. Gen Dent 2015;63(2):71-4.

[17] Sabins RA, Johnson JD, Hellstein JW. A comparison of the cleaning efficacy of short-term sonic and ultrasonic passive irrigation after hand instrumentation in molar root canals. J Endod 2003;29(10):674-8.

[18] Kumar VR, Bahuguna N, Manan R. Comparison of efficacy of various root canal irrigation systems in removal of smear layer generated at apical third: an SEM study. J Conserv Dent 2015;18(3):252-6.

[19] Koch JD, Smith NA, Garces D, et al. In vitro particle image velocity measurements in a model root canal: flow around a polymer rotary finishing file. J Endod 2014;40(3):4126.

[20] Koch J, Borg J, Mattson A, et al. An in vitro comparative study of intracanal fluid motion and wall shear stress induced by ultrasonic and polymer rotary finishing files in a simulated root canal model. ISRN Dent 2012;2012:764041.

[21] Singh N, Chandra A, Tikku AP, et al. A comparative evaluation of different irrigation activation systems on smear layer removal from root canal: an in vitro scanning electron microscope study. J Conserv Dent 2014;17(2):159-63. 